\title{
SYNTHESIS AND CHARACTERIZATION OF TRANSITION METAL COMPLEXES WITH A TETRAAZA MACROCYCLIC LIGAND: INHIBITORY ACTIVITY AGAINST SOME FUNGI
}

\author{
Anil Kumar ${ }^{1}$, Sulekh Chandra ${ }^{2 *}$ \\ ${ }^{1}$ Department of Chemistry Mewar University Gangrar, Chittorgarh, Rajasthan, India, 312901 \\ 2Zakir Husain Delhi College (University of Delhi), JLN Marg, New Delhi 110002
}

\begin{abstract}
$\mathrm{Co}(\mathrm{II}), \mathrm{Ni}(\mathrm{II})$ and $\mathrm{Cu}(\mathrm{II})$ complexes were synthesized with a tetraaza macrocyclic ligand i.e. 1,5-dioxo-9,10-diaza-3,oltribenzo- $(7,6,10,11,14,15)$ peptadecane. The ligand was characterized on the basis of elemental analysis, IR, $1 \mathrm{H}$ NMR, ESI Mass studies while the complexes were characterized by elemental analysis, molar conductance measurements, magnetic susceptibility measurements, IR, electronic and EPR spectral studies. The molar conductance values of the complexes indicate the non-electrolyte nature and the complexes may be formulated as $\left[\mathrm{M}(\mathrm{L}) \mathrm{X}_{2}\right]$, where $\mathrm{M}=\mathrm{Co}(\mathrm{II}), \mathrm{Ni}(\mathrm{II}), \mathrm{Cu}(\mathrm{II})$ and $\mathrm{X}=\mathrm{Cl}^{-}$and $\mathrm{NO}_{3}{ }^{-}$. On the basis of spectral studies, an octahedral geometry has been assigned for the $\mathrm{Co}(\mathrm{II})$ and $\mathrm{Ni}$ (II) complexes, whereas tetragonal geometry was found for $\mathrm{Cu}$ (II) complexes. In vitro antifungal activity was evaluated for the ligand and its complexes against some pathogenic fungi to assess their growth inhibiting potential.
\end{abstract}

Keywords: IR and NMR spectra, Co Ni Cu Antifungal screening.

\section{INTRODUCTION}

The field of macrocyclic chemistry is developing very rapidly because of its applications and importance in the area of coordination chemistry [1,2]. The stability of macrocyclic metal complexes depends upon a number of factors, including the number and types of donor atoms present in the ligand and their relative positions with in the macrocyclic skeleton, as well as the number and size of the chelate rings formed on complexation [3]. Macrocyclic complexes are thermodynamically more stable and more selective metal ion chelates than open chain analogue so the study of macrocyclic complexes is a growing class of research [4-6]. In living systems, metal ions play an important role as catalyst for many biological reactions. Macrocyclic complexes of transition metal ions have received great attention due to their biological activities, including antiviral, anticarcinogenic, antifertile, antibacterial and antifungal [7-13].

\section{*Corresponding author: \\ Email: schandra00@yahoo.com}

http://dx.doi.org/10.20530/IJTA $33 \quad 40-48$

ISSN 2320-138X @ 2016
Therefore, it is worthwhile to carry out the synthesis and study the spectral properties of the macrocyclic ligand derived from salicylaldehyde, 1,3-dichloro-2propanol and $o$-phenylenediamine. The goal of the study presented here is to synthesize the $\mathrm{Co}(\mathrm{II}), \mathrm{Ni}(\mathrm{II})$ and $\mathrm{Cu}(\mathrm{II})$ metal complexes of synthesized macrocyclic ligand and to provide a baseline of structural data using various spectroscopic techniques and antifungal activity.

\section{MATERIALS AND METHOD}

All the chemicals were used of Anala $R$ grade and received from Sigma-Aldrich and Fluka. Metal salts were purchased from E. Merck and used as received.

\section{Synthesis of Ligand}

Synthesis of 2-[3-(-formyl phenoxy)-2hyroypropoxy] benzaldehyde (I)

The compound I was prepared by the method reported in the literature [14]. A solution of $\mathrm{NaOH}$ $(8.0 \mathrm{~g}, 0.2 \mathrm{~mol})$ in water $(400 \mathrm{~mL})$ was added to a ethanolic solution of salicylaldehyde $(20.98 \mathrm{~mL}, 0.2$ mol). The resulting solution was heated up to 55-60 

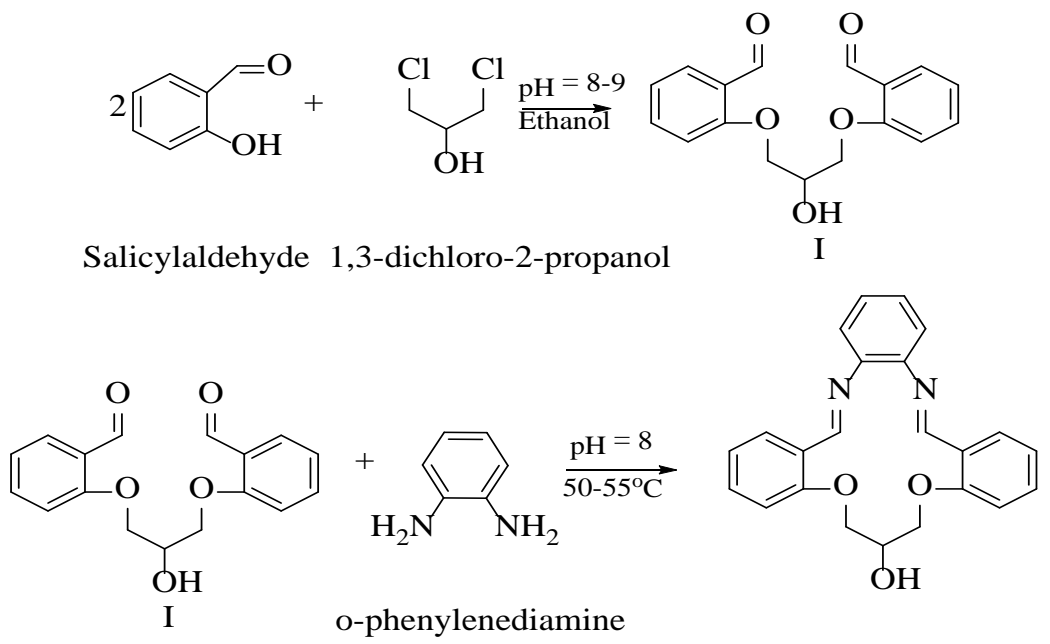

Scheme 1 Synthesis of macrocyclic ligand (L)

${ }^{\circ} \mathrm{C}$ for $1 \mathrm{~h}$ and then 1,3-dichloro-2-propane $(9.54 \mathrm{~mL}$, $0.1 \mathrm{~mol}$ ) was added. The solution was made homogenous by addition of sufficient amount of ethanol. The resulting solution was refluxed for $72 \mathrm{~h}$ $(\mathrm{pH} \cong 8-9)$ at $78{ }^{\circ} \mathrm{C}$ and then cooled at $0{ }^{\circ} \mathrm{C}$. The cream colored solid product was recrystalized in ethanol-water (2:1). The resulting product was collected by filtration and dried in a vacuum over $\mathrm{P}_{4} \mathrm{O}_{10}$.

\section{Synthesis of macrocyclic ligand (L)}

To a hot ethanolic solution $(20 \mathrm{~mL})$ of 2-[3-(-formyl phenoxy)-2-hyroypropoxy] benzaldehyde (I) (6 g, $0.02 \mathrm{~mol})$, a hot solution of o-phenyldiamine ( $2.162 \mathrm{~g}, 0.02 \mathrm{~mol}$ ) was added with constant stirring. The solution was heated at $50-55^{\circ} \mathrm{C}(\mathrm{pH} \cong 8)$ for $8 \mathrm{~h}$. On cooling at $0^{\circ} \mathrm{C}$, an solid product was precipated out. It was filtered, washed several times with cold ethanol and dried over $\mathrm{P}_{4} \mathrm{O}_{10}$ (Scheme 1).

\section{Synthesis of metal complexes}

Hot ethanolic solution $(20 \mathrm{~mL})$ of metal salts (1 $\mathrm{mmol}$ ) was added drop wise to a magnetically stirred solution of macrocyclic ligand $\mathbf{L}(1 \mathrm{mmol})$ in ethanol $(30 \mathrm{~mL})$. The resultant mixture was refluxed for $36 \mathrm{~h}$ and the clear solution was allowed to cool at $0{ }^{\circ} \mathrm{C}$.
The solid product precipitated out which was filtered, washed with ethanol, diethyl ether and dried under vacuum over $\mathrm{P}_{4} \mathrm{O}_{10}$. The same method was used for the preparation of metal complexes 26 in metal : ligand (1:1). Physical, analytical and spectral data of ligands and metal complexes are given in Table 1.

\section{Analysis}

The carbon and hydrogen were analyzed on CarloErba 1106 elemental analyzer. The nitrogen content of the complexes was determined using Kjeldahl's method. Molar conductance was measured on the ELICO (CM82T) conductivity bridge. ESI-MS spectra were obtained using a VG Biotech Quattrro mass spectrometer equipped with an elctrospray ionisation source in the mass range of $\mathrm{m} / z 100$ to $m / z$ 1000. IR spectra (CsI) were recorded on FTIR spectrum BX-II spectrophotometer. NMR spectrum was recorded with a model Bruker Avance DPX-300 spectrometer operating at $400 \mathrm{MHz}$ using DMSO-d6 as a solvent and TMS as internal standard. The electronic spectra were recorded in DMSO on Shimadzu UV mini-1240 spectrophotometer. EPR spectra was recorded on E4-EPR spectrometer at room temperature using DPPH as standard. 
Antifungal activity

The preliminary fungitoxicity activity of macrocyclic ligand and its complexes were examined by Poison Food Technique [15]. Fusarium oxysporum, Rhizoctonia solani and Botrytis cinerea were used for test fungi. The stock solution of the compound was directly mixed into the PDA (Potato Dextrose Agar) medium at the tested concentration.

Chlorothalonil used as commercial fungicide and DMSO served as control.

Potato dextrose agar medium was prepared by using potato, dextrose, agar-agar and distilled water. Appropriate quantities of the compounds in DMSO was added to potato dextrose agar medium in order to get a concentrations of 100, 200 and $300 \mathrm{ppm}$ of compound in the medium. The medium was poured into a set of two petriplates under aseptic conditions in a laminar flow hood. When the medium in the plates was solidified, a mycelial discs of $0.5 \mathrm{~cm}$ in diameter cut from the periphery of the 7 day old culture and it was aseptically inoculated upside down in the centre of the petriplates. These treated petriplates were incubated at $28 \pm 1{ }^{\circ} \mathrm{C}$ until fungal growth in the control

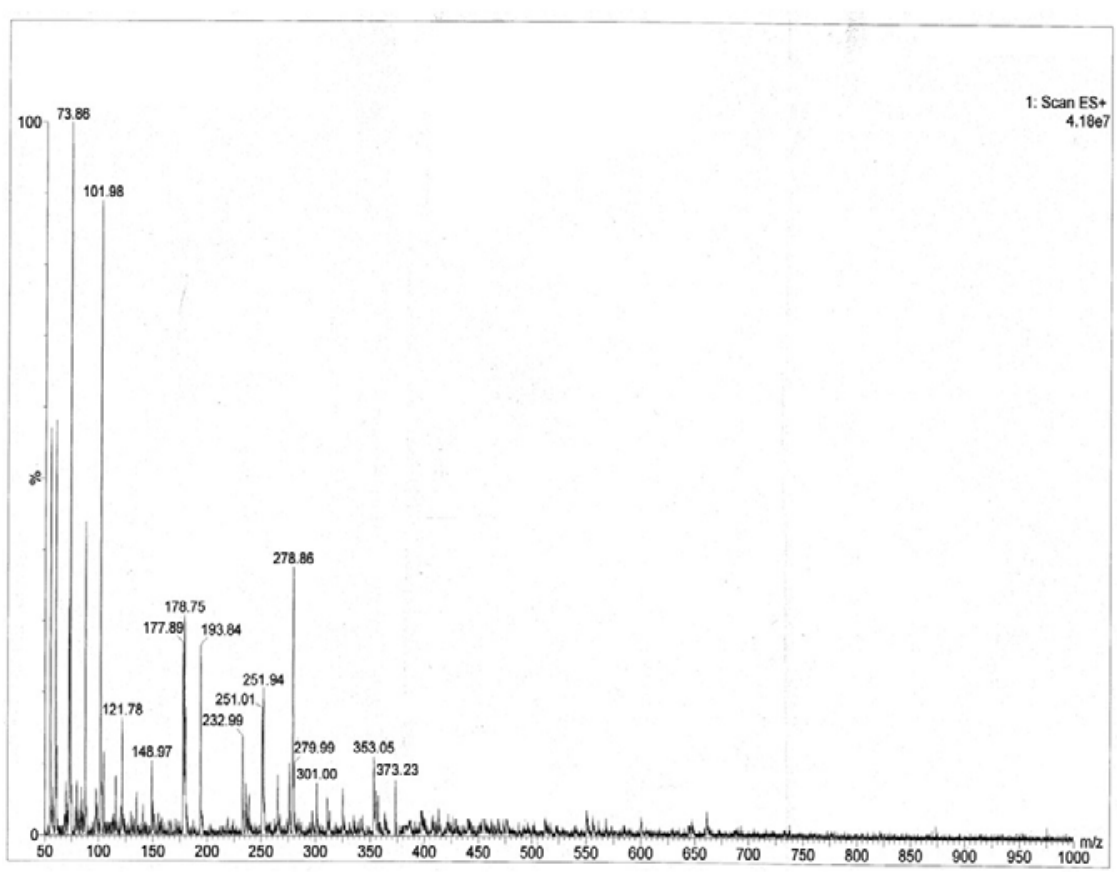

Fig. 1. Mass spectrum of the macrocyclic ligand $L$

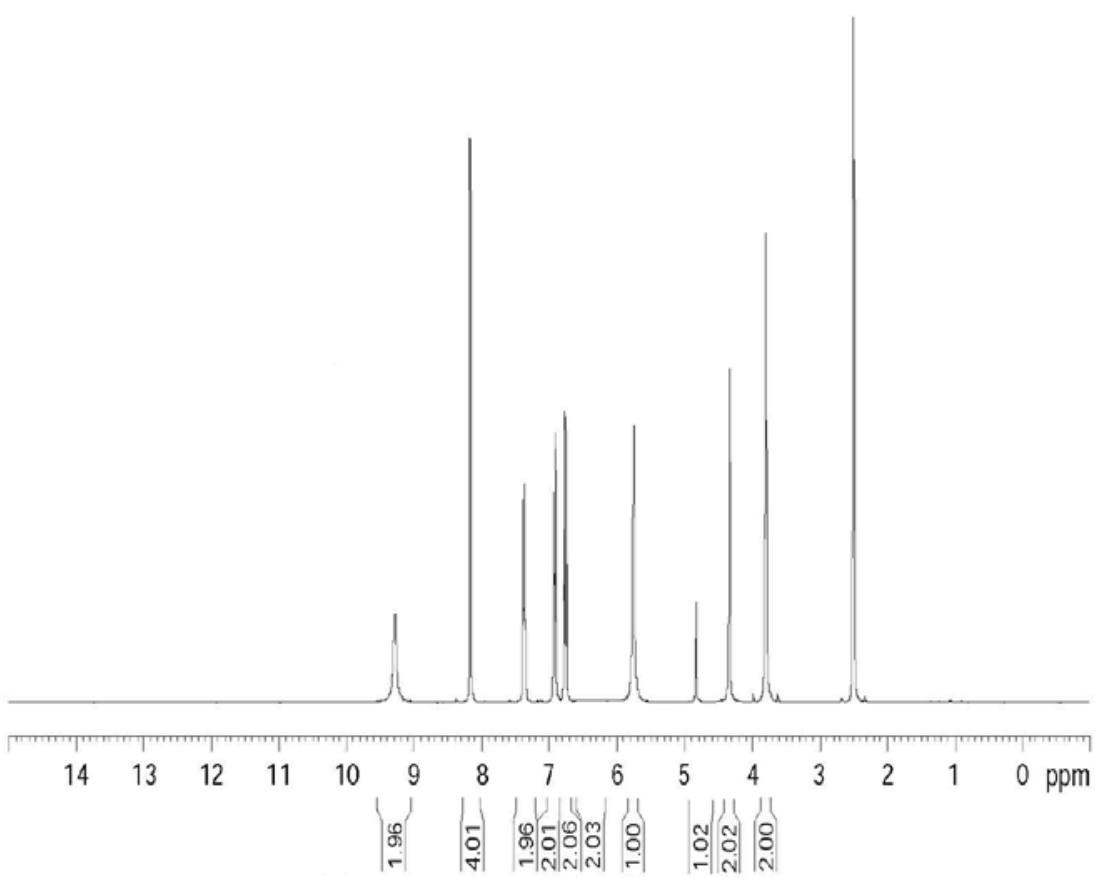

Fig. 2. ${ }^{1} \mathrm{H}$ NMR of ligand L 
petriplates was almost complete. The inhibition of the fungal growth expressed in percentage terms was determined from the growth in the test plate relative to the respective control plate as given below:

Inhibition (\%) $=(\mathrm{C}-\mathrm{T}) \times 100 / \mathrm{C}$

where $\mathrm{C}=$ diameter of fungal growth in the control plate and $T=$ diameter of fungal growth in the test

Table 1: Physical and Analytical data of Ligand $L$ and metal complexes 1-6

\begin{tabular}{|c|c|c|c|c|c|c|c|c|}
\hline \multirow[t]{2}{*}{ No } & \multirow[t]{2}{*}{ Molecular Formula } & \multirow[t]{2}{*}{ Color } & \multirow[t]{2}{*}{ Yield } & \multirow{2}{*}{$\begin{array}{c}\text { M. Pt } \\
\left({ }^{\circ} \mathrm{C}\right)\end{array}$} & \multicolumn{4}{|c|}{ Elemental Analysis (\%) found (calc.) } \\
\hline & & & & & C & H & $\mathbf{N}$ & $\mathbf{M}$ \\
\hline \multirow[t]{2}{*}{$\mathbf{L}$} & $\mathrm{C}_{23} \mathrm{H}_{20} \mathrm{~N}_{2} \mathrm{O}_{3}$ & Orange & 68 & 212 & 74.12 & 5.45 & 7.48 & - \\
\hline & & & & & (74.18) & $(5.41)$ & $(7.52)$ & \\
\hline \multirow[t]{2}{*}{1} & $\mathrm{Ni}(\mathrm{L}) \mathrm{Cl}_{2}$ & Green & 54 & $<280$ & 55.12 & 4.11 & 5.51 & 11.65 \\
\hline & $\mathrm{C}_{23} \mathrm{H}_{20} \mathrm{Cl}_{2} \mathrm{~N}_{2} \mathrm{NiO}_{3}$ & & & & $(55.03)$ & $(4.02)$ & $(5.58)$ & (11.69) \\
\hline \multirow[t]{2}{*}{2} & $\mathrm{Ni}(\mathrm{L})\left(\mathrm{NO}_{3}\right) 2$ & Light & 62 & $<280$ & 49.84 & 3.65 & 10.15 & 10.51 \\
\hline & $\left(\mathrm{C}_{23} \mathrm{H}_{20} \mathrm{~N}_{4} \mathrm{NiO}_{9}\right)$ & Green & & & $(49.76)$ & $(3.63)$ & (10.09) & $(10.57)$ \\
\hline \multirow[t]{2}{*}{3} & $\mathrm{Co}(\mathrm{L}) \mathrm{Cl}_{2}$ & Pink & 65 & $<280$ & 55.04 & 4.03 & 5.63 & 11.78 \\
\hline & $\mathrm{C}_{23} \mathrm{H}_{20} \mathrm{Cl}_{2} \mathrm{CoN}_{2} \mathrm{O}_{3}$ & & & & $(55.00)$ & $(4.01)$ & $(5.58)$ & (11.73) \\
\hline \multirow[t]{2}{*}{4} & $\mathrm{Co}(\mathrm{L})\left(\mathrm{NO}_{3) 2}\right.$ & Pink & 67 & $<280$ & 49.75 & 3.59 & 10.15 & 10.65 \\
\hline & $\left(\mathrm{C}_{23} \mathrm{H}_{20} \mathrm{CoN}_{4} \mathrm{O}_{9}\right)$ & & & & $(49.75)$ & (3.63) & (10.09) & (10.61) \\
\hline \multirow[t]{2}{*}{5} & $\mathrm{Cu}(\mathrm{L}) \mathrm{Cl}_{2}$ & Blue & 57 & $<280$ & 54.55 & 3.92 & 5.51 & 12.50 \\
\hline & $\mathrm{C}_{23} \mathrm{H}_{20} \mathrm{Cl}_{2} \mathrm{CuN}_{2} \mathrm{O}_{3}$ & & & & $(54.50)$ & (3.98) & $(5.53)$ & (12.54) \\
\hline \multirow[t]{2}{*}{6} & $\mathrm{Cu}(\mathrm{L})\left(\mathrm{NO}_{3) 2}\right.$ & Blue & 68 & $<280$ & 49.37 & 3.55 & 10.06 & 11.29 \\
\hline & $\left(\mathrm{C}_{23} \mathrm{H}_{20} \mathrm{CuN}_{4} \mathrm{O}_{9}\right)$ & & & & $(49.33)$ & $(3.60)$ & (10.01) & (11.35) \\
\hline
\end{tabular}

Table 2: Magnetic Moment (BM) and Electronic Spectral data $\left(\mathrm{cm}^{-1}\right)$ and Ligand Field parameter of the complexes

\begin{tabular}{ccccccccc}
\hline Complex & $\mu_{\text {eff }}$ (BM) & \multicolumn{3}{c}{ Electronic data $\left(\mathrm{cm}^{-1}\right)$} & \multicolumn{5}{c}{ Ligand Field Parameter } \\
\hline & & $\mathrm{U}_{1}$ & $\mathrm{U}_{2}$ & $\mathrm{U}_{3}$ & $\mathrm{Dq}\left(\mathrm{cm}^{-1}\right)$ & $\mathrm{B}\left(\mathrm{cm}^{-1}\right)$ & $\mathrm{B}$ & LFSE $\left.(\mathrm{kJmol})^{-1}\right)$ \\
\cline { 3 - 9 } 1 & 4.89 & 10470 & 16702 & 21188 & 1177.1 & 532 & 0.70 & 112.50 \\
2 & 4.99 & 10383 & 16325 & 18621 & 984.2 & 784 & 0.48 & 94.07 \\
3 & 2.86 & 11248 & 18621 & 21412 & 1124.8 & 419 & 0.40 & 161.26 \\
4 & 2.92 & 11185 & 18688 & 27322 & 1118.5 & 830 & 0.79 & 160.36 \\
5 & 1.98 & 12380 & 18268 & 24645 & - & - & - & - \\
6 & 1.95 & 15250 & 19467 & 26345 & - & - & - & -
\end{tabular}


Table 3 . EPR spectral data of the $\mathrm{Co}(\mathrm{II})$ and $\mathrm{Cu}(\mathrm{II})$ complexes

\begin{tabular}{cccccc}
\hline Complex & Temp. & \multicolumn{3}{c}{ Data as polycrystalline sample } & G \\
\cline { 3 - 5 } & & $\mathbf{g}_{\|}$ & $\mathbf{g}_{\perp}$ & $\mathbf{g}_{\text {iso }}$ \\
\cline { 3 - 5 } 1 & LNT & - & - & 2.1430 & - \\
2 & LNT & - & - & 2.1004 & - \\
5 & RT & 2.0853 & 2.0597 & - & 1.4288 \\
6 & RT & 2.1182 & 2.0669 & - & 1.7668 \\
\hline
\end{tabular}

plate.

\section{RESULTS AND DISCUSSION}

The macrocyclic ligand $L$ (Scheme 1) was prepared by mixing hot ethanolic solution $(20 \mathrm{~mL})$ of 2-[3-(formyl phenoxy)-2-hyroypropoxy] benzaldehyde (I) $(6 \mathrm{~g}, 0.02 \mathrm{~mol})$, a hot solution of o-phenyldiamine ( $2.162 \mathrm{~g}, 0.02 \mathrm{~mol}$ ) was added with constant stirring. The solution was heated at $50-55^{\circ} \mathrm{C}(\mathrm{pH} \cong 8)$ for $8 \mathrm{~h}$. On cooling at $0^{\circ} \mathrm{C}$, an solid product was precipated out. It was filtered, washed several times with cold ethanol and dried over $\mathrm{P}_{4} \mathrm{O}_{10}$ (Scheme 1). The structure of ligand thus formed was established by $I R,{ }^{1} \mathrm{H}$ NMR, Mass spectrophotometry and Analytical data (Table 1). The molar conductance value of complexes 1-6 lie in the range of 8.4-11.3 $\left(\Omega^{-1} \mathrm{~cm}^{2} \mathrm{~mol}^{-1}\right)$, which indicates their non electrolytic nature.

\section{Mass Spectrum}

The ESI mass spectrum of ligand $L$ showed a molecular ion peak at $\mathrm{m} / \mathrm{z}=373.23 \mathrm{amu}$ corresponding to $[\mathrm{M}+\mathrm{H}]^{+}$, which confirms the proposed formula (Figure 1). It also shows a series of peaks at 353.05, 301.0, 278.86, 251.94, 232.99, $178.75,121.78,101.98$ and 73.86 corresponding to various fragments. The intensities of these peaks give the idea of the stability of the fragments.

\section{${ }^{1}$ H NMR Spectrum}

The ${ }^{1} \mathrm{H}$ NMR spectrum was recorded for ligand $L$ (Figure 2). The characteristic signals, due to azomethine protons appear as singlet $9.28 \mathrm{ppm}$. The aromatic region is a set of doublets and multiplets in the range $6.74-8.16 \mathrm{ppm}$, while the aliphatic proton appear in the range of $3.79-4.88 \mathrm{ppm}$. The $\mathrm{D}_{2} \mathrm{O}$ exchangeable $-\mathrm{OH}$ proton shows a singlet at 5.78 ppm. All the proton peaks were found to be in their expected regions.

\section{IR Spectra}

The IR spectrum of the ligand was compared with those of the metal complexes in order to confirm the binding mode of the ligand to the corresponding metal ion. A very broad band at $3414 \mathrm{~cm}^{-1}$ in ligand L corresponds to $-\mathrm{OH}$ vibration, while the band for the $-\mathrm{CH}=\mathrm{N}$ - group appear at $1593 \mathrm{~cm}^{-1}$. However, in metal complexes 1-6, this band shifts to lower wave number in range of $1570-1577 \mathrm{~cm}^{-1}$, which indicates the coordination of azomethine nitrogen to metal ion [16]. This is also supported by the appearance of new band corresponds to $\mathrm{M}-\mathrm{N}$ bond in the region of $492-503 \mathrm{~cm}^{-1}$. Similarly, appearance of new band in the region of $570-592 \mathrm{~cm}^{-1}$ corresponds to $\mathrm{M}-\mathrm{O}$ bond [17].

The presence of bands at 1450-1410 $\left(\mathrm{v}_{5}\right), 1348-1320$ $\left(v_{1}\right)$ and $1058-1025\left(v_{2}\right) \mathrm{cm}^{-1}$, in the IR spectra of the metal complex 2, 4 and 6 suggests that both the nitrate groups are coordinated to the central metal ion in a unidentate fashion [18]. The chloro complexes show the IR bands in the region 340-385 $\mathrm{cm}^{-1}$ due to $v(\mathrm{M}-\mathrm{Cl}$ bond [19]. The IR spectral data indicates that the ligand $L$ coordinates to metal ion in tetradentate fashion. Based on above interpretation following structure can be proposed for metal complexes (Figure 3). 
Table 4. Antifungal activities data of the macrocyclic ligand and it complexes

\begin{tabular}{|c|c|c|c|c|}
\hline \multirow[t]{2}{*}{ Compounds } & \multirow[t]{2}{*}{$\begin{array}{c}\text { Fungus species } \\
\text { (tested ) }\end{array}$} & \multicolumn{3}{|c|}{$\begin{array}{c}\text { Fungal inhibition (\%) } \\
\text { Concentrations }\left(\mu \mathrm{gl}^{-1}\right)\end{array}$} \\
\hline & & 100 & 200 & 300 \\
\hline \multirow[t]{4}{*}{$\mathbf{L}$} & F. oxysporum & $40 \pm 4$ & $51 \pm 4$ & $58 \pm 6$ \\
\hline & R. solani & $49 \pm 2$ & $63 \pm 6$ & $71 \pm 3$ \\
\hline & B. cinerea & $47 \pm 6$ & $57 \pm 2$ & $67 \pm 4$ \\
\hline & F. oxysporum & $50 \pm 3$ & $65 \pm 2$ & $73 \pm 4$ \\
\hline \multirow[t]{3}{*}{1} & R. solani & $52 \pm 6$ & $60 \pm 4$ & $75 \pm 2$ \\
\hline & B. cinerea & $61 \pm 6$ & $69 \pm 5$ & $80 \pm 3$ \\
\hline & F. oxysporum & $49 \pm 3$ & $56 \pm 3$ & $72 \pm 4$ \\
\hline \multirow[t]{3}{*}{2} & R. solani & $54 \pm 4$ & $65 \pm 5$ & $77 \pm 2$ \\
\hline & B. cinerea & $56 \pm 4$ & $61 \pm 5$ & $78 \pm 5$ \\
\hline & F. oxysporum & $59 \pm 2$ & $72 \pm 6$ & $81 \pm 3$ \\
\hline \multirow[t]{3}{*}{3} & R. solani & $75 \pm 6$ & $81 \pm 4$ & $89 \pm 2$ \\
\hline & B. cinerea & $65 \pm 2$ & $76 \pm 4$ & $85 \pm 3$ \\
\hline & F. oxysporum & $63 \pm 3$ & $77 \pm 3$ & $89 \pm 6$ \\
\hline \multirow[t]{3}{*}{4} & R. solani & $71 \pm 4$ & $78 \pm 2$ & $88 \pm 6$ \\
\hline & B. cinerea & $60 \pm 3$ & $71 \pm 5$ & $89 \pm 5$ \\
\hline & F. oxysporum & $68 \pm 6$ & $77 \pm 5$ & $98 \pm 3$ \\
\hline \multirow[t]{3}{*}{5} & R. solani & $75 \pm 6$ & $89 \pm 3$ & $92 \pm 4$ \\
\hline & B. cinerea & $68 \pm 2$ & $85 \pm 2$ & $95 \pm 6$ \\
\hline & F. oxysporum & $71 \pm 5$ & $82 \pm 2$ & $99 \pm 4$ \\
\hline \multirow[t]{3}{*}{6} & R. solani & $75 \pm 5$ & $89 \pm 6$ & $95 \pm 3$ \\
\hline & B. cinerea & $64 \pm 3$ & $86 \pm 4$ & $99 \pm 3$ \\
\hline & F. oxysporum & $69 \pm 0$ & $79 \pm 2$ & $97 \pm 1$ \\
\hline \multirow[t]{2}{*}{ Chlorothalonil } & R. solani & $72 \pm 1$ & $85 \pm 2$ & $96 \pm 0$ \\
\hline & B. cinerea & $65 \pm 2$ & $82 \pm 0$ & $100 \pm 1$ \\
\hline
\end{tabular}

${ }^{\mathrm{a}}$ The results are expressed as the percentage of fungal inhibition with respect to control and are presented as mean \pm SD

\section{Magnetic moments}

At room temperature the magnetic moment of cobalt(II) complexes lie in the range 4.89-4.99 BM which correspond to three unpaired electrons. $\mathrm{Ni}(\mathrm{II})$ complexes show magnetic moment in the range 2.86-2.92 BM corresponding to two unpaired electron. At room temperature $\mathrm{Cu}(\mathrm{II})$ complexes show magnetic moment in the range 1.95-1.98 BM corresponding to one unpaired electron [20].

\section{Electronic spectra}

The electronic spectra of the complexes were recorded in DMSO solutions. The electronic spectral data of the complexes are given in Table 4. The electronic spectra of cobalt(II) complexes display the $d-d$ transition bands in the region 10,383-10,471, $16,325-16,702$ and $18,621-$ $21,188 \mathrm{~cm}^{-1}$. These transitions may be assigned to the ${ }^{4} \mathrm{~T}_{1 \mathrm{~g}}(\mathrm{~F}) \rightarrow{ }^{4} \mathrm{~T}_{2 \mathrm{~g}}(\mathrm{~F}) \mathrm{V}_{1}$, ${ }^{4} \mathrm{~T}_{1 \mathrm{~g}}(\mathrm{~F}) \rightarrow{ }^{4} \mathrm{~A}_{2 \mathrm{~g}}$ (F) $\mathrm{v}_{2}$ and ${ }^{4} \mathrm{~T}_{1 \mathrm{~g}}(\mathrm{~F}) \rightarrow{ }^{4} \mathrm{~T}_{1 \mathrm{~g}}$ (P) v3, respectively. These transitions correspond to the octahedral geometry around the $\mathrm{Co}(\mathrm{II})$ metal ion [21].

The absorption spectra of nickel(II) complexes display three $\mathrm{d}$ - $\mathrm{d}$ transition bands in the range $11,185-11,248$, $18,621-18,688$ and $21,412-27,322 \mathrm{~cm}^{-1}$. These transitions correspond to the ${ }^{3} \mathrm{~A}_{2 \mathrm{~g}}(\mathrm{~F}) \rightarrow{ }^{3} \mathrm{~T}_{2 \mathrm{~g}}(\mathrm{~F}) \mathrm{v}_{1},{ }^{3} \mathrm{~A}_{2 \mathrm{~g}}$ (F) $\rightarrow{ }^{3} \mathrm{~T}_{1 \mathrm{~g}}$ (F) $v_{2}$ and ${ }^{3} \mathrm{~A}_{2 \mathrm{~g}}(\mathrm{~F})$ $\rightarrow{ }^{3} \mathrm{~T}_{1 \mathrm{~g}}$ (P) $\mathrm{V}_{3}$, respectively [22]. These transitions reveal that the nickel complexes possess an octahedral geometry.

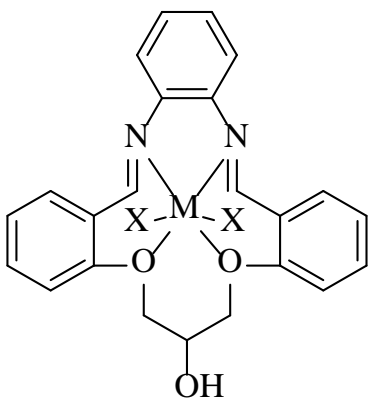

$\mathrm{M}=\mathrm{Ni}, \mathrm{Co}$, and $\mathrm{Cu} ; \mathrm{X}=\mathrm{Cl}^{-1}, \mathrm{NO}_{3}{ }^{-1}$

Figure 3: Proposed structured of metal complexes 
Electronic spectra of $\mathrm{Cu}(\mathrm{II})$ complexes show the $\mathrm{d}-\mathrm{d}$ transition bands in the range 12,380-15,250, 18,268-19,467 and 24,645-26,345 $\mathrm{cm}^{-1}$. These bands correspond to ${ }^{2} B_{1 g} \rightarrow{ }^{2} A_{1 g} \quad\left(d_{x 2-y_{2}} \rightarrow d_{z 2}\right)$, ${ }^{2} \mathrm{~B}_{1 \mathrm{~g}} \rightarrow{ }^{2} \mathrm{~B}_{2 \mathrm{~g}}\left(\mathrm{~d}_{\mathrm{x} 2-\mathrm{y} 2} \rightarrow \mathrm{d}_{\mathrm{xy}}\right)$ and ${ }^{2} \mathrm{~B}_{1 \mathrm{~g}} \rightarrow{ }^{2} \mathrm{E}_{\mathrm{g}}\left(\mathrm{d}_{\mathrm{x} 2-\mathrm{y} 2} \rightarrow \mathrm{d}_{\mathrm{xz}}, \mathrm{d}_{\mathrm{yz}}\right)$ transitions, respectively [23]. On the basis of electronic transitions, a tetragonal geometry is suggested for $\mathrm{Cu}(\mathrm{II})$ complexes.

The ligand field parameters like Racah interelectronic repulsion parameter $B$, ligand field splitting stabilization energy $10 \mathrm{Dq}$, covalency factor $\beta$ and ligand field stabilization energy (LFSE) have been calculated for the $\mathrm{Co}(\mathrm{II})$ and $\mathrm{Ni}(\mathrm{II})$ complexes. The values of $\mathrm{B}$ and $\mathrm{Dq}$ of $\mathrm{Co}$ (II) complexes were calculated from the transition energy ratio diagram using $v_{3} / v_{1}$ ratio. The value of $\beta$ for the complexes under study accounts for the covalent nature of the complexes [24]. The evaluated parameters are listed in Table 2.

\section{EPR Spectrum}

The X-band EPR spectra of the Co(II) complexes were recorded at liquid nitrogen temperature in polycrystalline form. The line shaped EPR spectra of Co(II) complexes show the value of $g_{\text {iso }}=$ 2.1004-2.1430 (Table 3) around the Co(II) atoms.. The large deviation in the $g$ values from the free electron value $(g=2.0023)$ is due to large angular momentum contribution.

EPR spectra of the Cu(II) complexes were recorded, at room temperature as polycrystalline samples, on the $\mathrm{X}$-band at $9.1 \mathrm{GHz}$ under the magnetic field range $3000 \mathrm{G}$. The trend $\mathrm{g}_{\| I}>\mathrm{g}_{\mathrm{I}}>2.0023$, observed for the complexes, under study, indicate that the unpaired electron is localized in the $d_{x 2-y 2}$ orbital of the $\mathrm{Cu}(\mathrm{II})$ ion and the spectral features are characteristic for the axial symmetry. Tetragonally elongated geometry is thus confirmed for the aforesaid complexes. $G=\left(g_{\|}-2\right) /\left(g_{\mid}-2\right)$, which measure the exchange interaction between the metal centers in a polycrystalline solid has been calculated. The complexes show the $G$ values smaller than 4 which indicate exchange interaction in the solid complexes [25].

\section{Antifungal Screening}

Results of anti-fungal screening as shown in Table 4 indicate that the metal complexes inhibit higher antifungal activity than controlled one. Among all of the screened samples, complex 5 and 6 were observed to have a significant anti-fungal activity at quite a low concentration and could be considered to be a broad spectrum anti-fungal compound. The increased activity of the metal chelates can be explained on the basis of chelation theory [26]. Chelation reduces the polarity of metal ion, mainly by the partial sharing of its positive charge with the chelate rings. It increases the lipophilic character of the metal, which subsequently favours its permeation through the lipid layer of microorganism membrane, thereby impairing the normal cell processes [27]. It has also been proposed that concentration plays a vital role in increasing the degree of inhibition; as the concentration increases, the activity increases [28].

\section{CONCLUSION}

$\mathrm{Co}(\mathrm{II}), \mathrm{Ni}(\mathrm{II})$ and $\mathrm{Cu}(\mathrm{II})$ complexes with a tetradentate macrocyclic ligand have been prepared and characterized by using various spectroscopic techniques. On the basis of above spectral studies an octahedral geometry has been assigned for Co(II) and $\mathrm{Ni}(\mathrm{II})$ complexes while tetragonal geometry for $\mathrm{Cu}$ (II) complexes. Various ligand field parameters have been calculated and discussed. Metal complexes show potentially activity towards microbial strains in comparison to free ligand.

\section{REFRENCES}

1. Gupta LK, Chandra S. Physicochemical and Biological Characterization of Transition Metal Complexes with Nitrogen Donor Tetra-dentate Novel Macrocyclic Ligand. Transition Metal Chemistry ; 2006 Apr;31(3):368-73. Available from: http://dx.doi.org/10.1007/s11243-0050002-0

2. Chandra S, Gautam A, Tyagi M. Synthesis and spectroscopic characterization of transition metal complexes of a 12-membered tetraaza 
[N4] macrocyclic ligand and their biological activity. Transition Metal Chemistry ; 2007 Aug 31;32(8):1079-84. Available from: http://dx.doi.org/10.1007/s11243-007-0289-0

3. Singh DP, Malik V, Kumar R, Kumar K. Synthesis and spectral study of biologically active macrocyclic complexes of divalent transition metal ions. Russian Journal of Coordination Chemistry ;36(3):220-5.

4. Template Synthesis and Characterization of Macrocyclic Complexes of Trivalent Metal Ions Derived from Oxalyldihydrazide and Isatin. Asian Journal of Chemistry ; 2014;26(2). Available from:

http://dx.doi.org/10.14233/ajchem.2014.15408

5. El-Boraey HA, EL-Gammal OA. New 15membered tetraaza (N4) macrocyclic ligand and its transition metal complexes: Spectral, magnetic, thermal and anticancer activity. Spectrochimica Acta Part A: Molecular and Biomolecular Spectroscopy ;138:553-62. Available from: http://dx.doi.org/10.1016/j.saa.201

6. Cheng QR, Yu L, Li P, Liao GY, Zhou H, Pan ZQ. Macrocyclic dinuclear nickel(II) and manganese(II) complexes: synthesis, X-ray crystal structures, DNA cleavage, and antimicrobial activity studies. Transition Metal Chemistry; 2015 Sep 30;40(8):789-97. Available from: http://dx.doi.org/10.1007/s11243-0159973-7

7. Shankarwar SG, Nagolkar BB, Shelke VA, Chondhekar TK. Synthesis, spectral, thermal and antimicrobial studies of transition metal complexes of 14-membered tetraaza[N4] macrocyclic ligand. Spectrochimica Acta Part A: Molecular and Biomolecular Spectroscopy ; 2015 Jun;145:188-93. Available from: http://dx.doi.org/10.1016/j.saa.2015.02.006

8. El-Gammal OA, Bekheit MM, El-Brashy SA. Synthesis, characterization and in vitro antimicrobial studies of $\mathrm{Co}(\mathrm{II}), \mathrm{Ni}(\mathrm{II})$ and $\mathrm{Cu}(\mathrm{II})$ complexes derived from macrocyclic compartmental ligand. Spectrochimica Acta Part A: Molecular and Biomolecular Spectroscopy ; 2015 Feb;137:207-19. Available from: http://dx.doi.org/10.1016/j.saa.2014.08.016
9. Tyagi M, Chandra S, Akhtar J, Chand D. (2015). Modern spectroscopic technique in the characterization of biosensitive macrocyclic schiff base ligand and its metal complexes: Inhibitory activity against some plantpathogenic fungi. Spectrochim Acta A, 118, 1056.

10. Verma S, Chandra S, Dev U, Joshi N. Synthesis, spectral and biological studies of nitrogensulphur donor macrocyclic ligands and their transition metals complexes. Spectrochimica Acta Part A: Molecular and Biomolecular Spectroscopy ;74(2):370-4. Available from: http://dx.doi.org/10.1016/j.saa.2009.06.029

11. Kumar G, Devi S, Johari R, Kumar D. Synthesis, spectral characterization and antimicrobial evaluation of Schiff base $\mathrm{Cr}$ (III), Mn (III) and Fe (III) macrocyclic complexes. European Journal of Medicinal Chemistry ; 2012 Jun;52:269-74. Available from: http://dx.doi.org/10.1016/j.ejmech.2012.03.025

12. Rathi P, Singh DP. Synthesis, antimicrobial, antioxidant and molecular docking studies of thiophene based macrocyclic Schiff base complexes. Journal of Molecular Structure ; 2015 Nov;1100:208-14. Available from: http://dx.doi.org/10.1016/j.molstruc.2015.07.0 25

13. Singh DP, Kumar K, Sharma C. Antimicrobial active macrocyclic complexes of $\mathrm{Cr}(\mathrm{III}), \mathrm{Mn}(\mathrm{III})$ and $\mathrm{Fe}(\mathrm{III})$ with their spectroscopic approach. European Journal of Medicinal Chemistry ; 2009 Aug;44(8):3299-304. Available from: http://dx.doi.org/10.1016/j.ejmech.2009.02.029

14. Armstrong LG, Lindoy LF. Nitrogen-oxygen donor macrocyclic ligands. I. Nickel(II) complexes of a new series of cyclic ligands derived from salicylaldehydes. Inorg Chemistry; 1975 Jun;14(6):1322-6. Available from: http://dx.doi.org/10.1021/ic50148a024

15. Rani S, Kumar S, Chandra S. Spectroscopic and biological approach in the characterization of a novel 14-membered [N4] macrocyclic ligand and its Palladium(II), Platinum(II), Ruthenium(III) and Iridium(III) complexes. Spectrochimica Acta Part A: Molecular and Biomolecular Spectroscopy ;118:244-50. Available from: http://dx.doi.org/10.1016/j.saa.2013.08.079 
16. Chandra S, Gupta LK, Jain D. Spectroscopic studies on $\mathrm{Mn}(\mathrm{II}), \mathrm{Co}(\mathrm{II}), \mathrm{Ni}(\mathrm{II})$, and $\mathrm{Cu}(\mathrm{II})$ complexes with $\mathrm{N}$-donor tetradentate (N4) macrocyclic ligand derived from ethylcinnamate moiety. Spectrochimica Acta Part A: Molecular and Biomolecular Spectroscopy ;60(10):2411-7. Available from: http://dx.doi.org/10.1016/j.saa.2003.12.016

17. Chandra S, Gupta LK. Spectroscopic characterization of tetradentate macrocyclic ligand: it's transition metal complexes. Spectrochimica Acta Part A: Molecular and Biomolecular Spectroscopy ;60(12):2767-74. Available from: http://dx.doi.org/10.1016/j.saa.2004.01.01

18. Chandra S, Gupta LK. Mass, IR, electronic and EPR spectral studies on transition metal complexes with a new tetradentate 12membered new macrocyclic ligand. Spectrochimica Acta Part A: Molecular and Biomolecular Spectroscopy ; 2004 Nov;60(13):3079-85. Available from: http://dx.doi.org/10.1016/j.saa.2004.01.030

19. Nelson JH. A review of: "Infrared and Raman Spectra of Inorganic and Coordination Compounds. 4th Fdition, Kazuo Nakamoto, Wiley-Interscience, New York, N.Y., 1986. XI + 484 pp., \$55.00."”. Synthesis and Reactivity in Inorganic and Metal-Organic Chemistry;17(2):239-239. Available from: http://dx.doi.org/10.1080/00945718708059428

20. Figgis BN. 648. Solutions for the calibration of gouy equipment. J Chem Soc; 1964;3423. Available from: http://dx.doi.org/10.1039/jr9640003423

21. Template Synthesis and Characterization of Macrocyclic Complexes of Trivalent Metal Ions Derived from Oxalyldihydrazide and Isatin. Asian Journal of Chemistry ; 2014;26(2). Available from:

http://dx.doi.org/10.14233/ajchem.2014.15408

22. Chandra S, Gautam A, Tyagi M. Synthesis, structural characterization, and antibacterial studies of a tetradentate macrocyclic ligand and Its $\mathrm{Co}(\mathrm{II}), \mathrm{Ni}(\mathrm{II})$, and $\mathrm{Cu}(\mathrm{II})$ complexes. Russian Journal of Coordination Chemistry;; 2009 Jan;35(1):25-9. Available from: http://dx.doi.org/10.1134/s107032840901006
23. El-Boraey HA, Emam SM, Tolan DA, El-Nahas AM. Structural studies and anticancer activity of a novel (N6O4) macrocyclic ligand and its $\mathrm{Cu}$ (II) complexes. Spectrochimica Acta Part A: Molecular and Biomolecular Spectroscopy ; 2011 Jan;78(1):360-70. Available from: http://dx.doi.org/10.1016/j.saa.2010.10.021

24. .23. Chandra S, Gupta LK, Jain D. Spectroscopic studies on $\mathrm{Mn}(\mathrm{II}), \mathrm{Co}(\mathrm{II}), \mathrm{Ni}(\mathrm{II})$, and $\mathrm{Cu}(\mathrm{II})$ complexes with $\mathrm{N}$-donor tetradentate (N4) macrocyclic ligand derived from ethylcinnamate moiety. Spectrochimica Acta Part A: Molecular and Biomolecular Spectroscopy ; 2004 Aug;60(10):2411-7. Available from: http://dx.doi.org/10.1016/j.saa.2003.12.016

25. Chandra S, Bargujar S, Nirwal R, Qanungo K, Sharma SK. Synthesis, spectral characterization, molecular modeling, thermal study and biological evaluation of transition metal complexes of a bidentate Schiff base ligand. Spectrochimica Acta Part A: Molecular and Biomolecular Spectroscopy ; 2013 Sep;113:164$70 . \quad$ Available from: http://dx.doi.org/10.1016/j.saa.2013.04.114

26. Rajavel R, Vadivu MS, Anitha C. Synthesis, Physical Characterization and Biological Activity of Some Schiff Base Complexes. E-Journal of Chemistry ; 2008;5(3):620-6. Available from: http://dx.doi.org/10.1155/2008/583487

27. Chandra S, Gupta LK, Agrawal S. Synthesis spectroscopic and biological approach in the characterization of novel [N4] macrocyclic ligand and its transition metal complexes. Transition Metal Chemistry; 2007 May 26;32(5):558-63. Available from: http://dx.doi.org/10.1007/s11243-007-0201-y

28. Singh D, Malik V, Kumar R, Kumar K. Template synthesis of macrocyclic complexes of Co(II), $\mathrm{Ni}(\mathrm{II}), \mathrm{Cu}(\mathrm{II}), \mathrm{Zn}(\mathrm{II})$ and $\mathrm{Cd}(\mathrm{II})$ : Spectroscopic, antibacterial and antifungal studies. Journal of the Serbian Chemical Society ; 2010;75(6):763 Available from: http://dx.doi.org/10.2298/jsc090901050s 